\title{
BMJ Open Emotional reserve and prolonged post- concussive symptoms and disability: a Swedish prospective 1-year mild traumatic brain injury cohort study
}

To cite: Oldenburg C, Lundin A, Edman G, et al. Emotional reserve and prolonged postconcussive symptoms and disability: a Swedish prospective 1-year mild traumatic brain injury cohort study. BMJ Open 2018;8:e020884. doi:10.1136/ bmjopen-2017-020884

- Prepublication history for this paper is available online. To view these files, please visit the journal online (http://dx.doi org/10.1136/bmjopen-2017020884).

Received 30 November 2017 Revised 12 March 2018 Accepted 1 June 2018
Check for updates

${ }^{1}$ Division of Rehabilitation Medicine, Department of Clinical Sciences, Danderyd Hospital, Karolinska Institutet, Stockholm, Sweden

${ }^{2}$ Neuropsychiatry Section, Dizziness Center, Stockholm,

Sweden

${ }^{3}$ Tiohundra AB, Norrtälje sjukhus, Norrtälje, Sweden

Correspondence to

Christian Oldenburg;

christian.oldenburg@ki.se

\section{ABSTRACT}

Objective Prolonged post-concussive symptoms (PCS) affect a significant minority of patients withmild traumatic brain injury (mTBI). The aetiology is multifactorial depending on preinjury as well as peri-injury and postinjury factors. In this study, we examine outcome from an emotional reserve perspective.

Design Prospective cohort study.

Setting Patients were recruited from three emergency departments in major university hospitals in Stockholm, Sweden. Follow-up data were collected in an outpatient setting at one of the recruiting hospitals.

Participants 122 patients with a history of blunt head trauma (aged 15-65 years; admitted for mTB within 24 hours after trauma (Glasgow Coma Scale score of 14-15, loss of consciousness $<30 \mathrm{~min}$ and/or post-traumatic amnesia $<24$ hours). Exclusion criteria were other significant physical injury and other major neurological disorder, including previous significant head injury.

Procedure Recruitment in three emergency departments. Initial assessments were made within 1 week after the injury. Patients were mailed the follow-up questionnaires 1 year postinjury.

Outcome measures A psychiatric assessment was performed at 1 week post injury. The participants also completed a personality inventory, measures of psychological resilience, depression, anxiety and posttraumatic symptoms. One-year outcome was measured by the Rivermead Post Concussion Symptoms and the Rivermead Head Injury Follow-Up questionnaires. Results The psychiatric assessment revealed more symptoms of anxiety, depression and post-traumatic symptoms in the acute stage for patients who later developed PCS. After 1 year, 94 participants were still in the programme (male/female 57/37) and $12 \%$ matched the extended criteria for PCS ( $\geq 3$ symptoms and $\geq 2$ disabilities). PCS patients reported more preinjury and concurrent psychiatric problems, lower level of functioning before the injury and experienced more stress. They showed higher somatic trait anxiety, embitterment, mistrust and lower level of psychological resilience than recovered participants.

Conclusion Intrapersonal emotional reserve shape the emergence and persistence of PCS after MTBI.
Strengths and limitations of this study

- Prospective design including relatively homogeneous consecutive patients (Glasgow Coma Scale score of 14-15), selected by injury criteria, not for postconcussive complaints, within the first 24 hours after the trauma.

- Individual standardised psychiatric assessment for the screening of current and preinjury psychiatric problems minimising recall bias by early follow-up ( $<1$ week after injury).

- Assessment of preinjury factors was performed without knowledge of late outcome.

- The number of patients with prolonged post-concussive symptoms and disability were few $(n=11)$, implying reduced power to detect differences when compared with recovered patients.

- Limited generalisability due to relatively high attrition rate $(23 \%)$ where patients with shorter formal education were more likely to drop out.

\section{INTRODUCTION}

The prognosis after a mild traumatic brain injury (mTBI) in general is beneficial. ${ }^{12}$ However, a noteworthy proportion of individuals continue to report post-concussive symptoms (PCS) for months, ${ }^{3}{ }^{4}$ years ${ }^{5}$ or even decades. ${ }^{6}$ The reason for the chronicity of the state is unclear. The hypothesis that PCS may be associated with acquired long-term cognitive deficits following mTBI has not been corroborated in meta-analyses. ${ }^{7-11}$ Instead, some research points to the possibility that PCS is linked to lower preinjury cognitive functioning, the so-called cognitive reserve. ${ }^{12-15}$ In other words, the conditions in the brain at the time of injury may be more important than previously assumed for the outcome and suggest an individual preinjury vulnerability for developing PCS.

Cognitive reserve is part of the larger construct brain reserve capacity, which was suggested by Paul Satz ${ }^{16}$ as a threshold model 
for understanding different clinical outcomes after seemingly similar brain insults or pathologies. However, while brain reserve is typically concerned with anatomical features of the brain (eg, brain volume, synaptic count and dendritic branching), cognitive reserve relates specifically to the active processes of the brain. ${ }^{17}$ Individuals with higher cognitive reserve might be better to cope with brain injury by using pre-existing, more efficient, cognitive processing abilities or by recruiting more unaffected networks in the brain in a compensatory manner. ${ }^{18}$ Variables that have been used as estimates of cognitive reserve are those associated with life-time experiences, ${ }^{18}$ such as educational and occupational attainment. These variables also relates heavily to socioeconomic status (SES), which has repeatedly been shown to influence health, regardless of whether the individual has suffered an injury or not. ${ }^{19}$

Gallo and Matthews ${ }^{20}$ suggested a Reserve-Capacity Model where the relation between low SES and health is explained. The model posits that people with lower SES are at a disadvantage in two ways: first, they are likely to experience more stress, both daily hassles, and major stressors; second, they also have fewer reserves to cope with that stress. Importantly, the authors suggest that the individual's intrapersonal reserves can act as a moderator and partly explain differences in health outcome, and they present evidence that a negative emotional state is linked to adverse health effects. In this perspective, we may think of an intrapersonal emotional reserve that, like the cognitive reserve, acts as a buffer against adverse subjective outcome and partly explain individual differences in outcome.

Emotional reserve is a hypothetical construct, and good proxies for measurement might be measures of disadvantageous personality traits and psychological resilience. Life circumstances that could be indicative of lower levels of emotional reserve could also include previous mental health problems.

Kay $e t a t^{21}$ in an early descriptive clinical study of vulnerability for PCS suggested personality traits such as overachievement, dependency, insecurity, grandiosity and borderline personality characteristics. Few studies have however systematically investigated the association between personality and PCS. Rush and coworkers ${ }^{22}$ using consecutive patients from an emergency care unit found that patients with mTBI had scored in the normal range of a personality inventory (NEO-Personality Inventory - Revised) and were not significantly different from a control group. They did not find any association between reported symptoms and personality variables. However, they did not examine a PCS group separately.

In a cross-sectional study of healthy participants with no prior brain injury $(\mathrm{n}=93)$, Garden $e t a l^{23}$ found that depressive, dependent, sadistic, negativistic, borderline, anxiety, somatic, dysthymia and major depression characteristics, as measured by the Millon Clinical Multiaxial Inventory-III were associated with a higher number of postconcussion-like symptoms. In a recent prospective cohort study, Yuen et $a l^{24}$ found a positive association between depressive and anxious personality traits and heightened PCS reporting after mTBI.

Psychological resilience has been described as an ability to recover from different adverse experiences. ${ }^{25}$ According to a recent review, there were only a few studies, with conflicting results, concerning resilience as a moderating factor for outcome after mTBI. ${ }^{26}$ In general, there was an association between higher resilience and less PCS. A Finnish prospective cohort study found that higher levels of resilience were associated with lower symptom reporting. ${ }^{25}$ Cross-sectional studies have found that lower levels of resilience are associated with higher symptom-reporting in participants who report having had a mTBI between 1 month and 6 months ago. ${ }^{27}$ Similar results have been found in a military veterans sample. ${ }^{28}$ However, in a prospective cohort study of emergency department patients, McCauley and colleagues ${ }^{29}$ found that higher levels of resilience at baseline ( $<24$ hours) was associated with higher symptom reporting. In this study though, PCS-like symptoms were collected earlier (1 month) postinjury, before the onset of the more chronic stages of PCS. ${ }^{30}$

There are various results regarding the influence of previous psychiatric conditions as a predictor of PCS. Luis $e a^{13}$ used a psychiatric interview in their sample of randomly selected Vietnam war veterans and found that a precombat history of psychiatric problems was more common for developing PCS. In a consecutive sample of emergency department visitors with mTBI, Meares et $a l^{3132}$ found that a preinjury depressive or anxiety disorder had an increased risk for PCS. Ponsford $e t a l^{33}$ also found that individuals with PCS, defined as highly distressed, tended to have more previous neurological or psychiatric problems. Stulemeijer et $a l^{15}$ studied a prospective sample of emergency department visitors with mTBI. Premorbid emotional problems were not significantly associated with PCS although close $(p=0.059)$. In this sample, 32\% reported a history of treatment with a psychologist, social worker or psychiatrist, or current use of psychotropic medication, or both, and supposedly broader inclusion criteria were applied. Snell $e t a l^{34}$ reported no association between preinjury psychiatric problems and worse outcome in a mixed sample of prospectively followed patients with mTBI in the emergency department as well as referred patients to a concussion clinic.

One reason for conflicting results in studies of PCS is different inclusion criteria, creating diverse prevalence rates in different studies. Some of the more usual symptoms (eg, headache, fatigue and memory problems) after mTBI are also common in other diagnostic groups and even in people who reports to be healthy. It is thus possible that criteria based only on symptom reporting is too lenient. We suggest that one way to sharpen PCS criteria is to require, in addition to symptoms, reporting of disability, in line with the Diagnostic and Statistical Manual of Mental Disorders-IV provisional diagnosis of 
postconcussive disorder requiring disability in at least two different areas in life. ${ }^{35}$

To conclude, there is a lack of research or conflicting results on the effect of preinjury emotional factors on outcome after mTBI. Vakil and his group ${ }^{36}$ examined several personality and emotional factors as components of reserve capacity in a group of patients with moderate to severe traumatic brain injury (TBI). They found moderating effects of these factors on outcome in addition to effects of injury severity.

We have previously reported ${ }^{12}$ an association between cognitive reserve and the development of PCS in a prospectively followed cohort of patients with mTBI. The aim of the present study was to investigate aspects of emotional reserve, psychological variables and psychiatric vulnerability and their association with a restrictively defined PCS group at 1 year postinjury in the same study group.

\section{METHOD}

\section{Participants}

This study reports data from a larger mTBI study where participants were recruited from three emergency departments during the period from January 2000 to December 2001. The study size was determined based on power calculations for differences on biomedical variables for patients with mTBI versus healthy controls. This have been reported previously. ${ }^{37}$ This study reports a subset of the data concerning 1-year outcome for patients with mTBI split into two outcome groups.

Inclusion criteria required visit to emergency department within 24 hours after blunt head trauma, with loss of consciousness (LOC) and/or post-traumatic amnesia (PTA), and a Glasgow Coma Scale (GCS) score of 14-15 at first assessment. Inclusion criteria were limited to GCS score of 14-15 to create a more homogenous group since previous studies have suggested that patients with GCS 13 should be considered as a moderate severity. ${ }^{38} 39$ Age range allowed for inclusion was 15-65 years. Exclusion criteria were any of the following: LOC $>30 \mathrm{~min}$, PTA $>24$ hours, other significant physical injury or other major neurological disorder, including a previous significant brain injury. Patients with high-velocity traumas were managed according to a regional trauma protocol and were not available for the study. No financial incentives were offered for participants, and no particular intervention was attached to the study.

PCS was defined as having three or more remaining symptoms on The Rivermead Post-Concussion Symptoms Questionnaire (RPQ), and two or more disabilities on The Rivermead Head Injury Follow-up Questionnaire (RHFUQ) at the 1-year follow-up. Patients who did not match the criteria for PCS was defined as recovered.

\section{Procedure}

Participants were recruited in the emergency department when they sought care for having suffered a blunt head trauma. Eligible participants were approached by the physician on duty. Daily visits of the research staff were aimed to decrease selection bias. After information about the study, informed consent was obtained from all participating patients. The emergency ward staff recorded GCS, duration of LOC, PTA and retrograde amnesia and the result of a blood alcohol test. CT scan of the brain was performed within 24 hours after admission, and an MRI scan of the brain was performed within 1 week. Scans were evaluated according to standard hospital routines by experienced radiologists. The data collection was exhaustive and included questionnaires, cognitive testing, psychiatric assessment and blood samples to test several hypotheses. However, data collection was distributed during several days to minimise fatigue. This report focuses on the following assessments: at day one, the RPQ was administered to measure initial symptom severity. A multiaxial psychiatric assessment (see below) and questionnaires were completed by the participants within 1 week postinjury. Finally, at 1 year postinjury, the participants were mailed the RPQ and RHFUQ and were instructed to complete and mail them back to the hospital. To maximise participation at follow-up, participants were reminded through a telephone call by the research nurse

\section{Measures}

Psychiatric assessment

Current and previous psychiatric diagnosis on Axis I and II according to DSM-IV were established in a semistructured clinical interview, performed by an experienced neuropsychiatrist (AL) taking also in consideration the risk for participators' bias and fatigue 1 week after the injury. General medical condition (Axis III) was assessed by a checklist survey, combined with a neurological examination to detect sequelae from the recent injury and to exclude other neurological disorders. Axis IV, psychosocial and environmental factors, was assessed by use of the Severity of Psychosocial Stressors Scale, completed by the participant. The scale addresses 11 potential areas of stress during the last year (eg, financial problems, marital problems and loss of a relative) and comprises 11 'yes' or 'no' questions. The experienced level of distress was rated on a graded scale with six options: none, mild, moderate, severe, extreme and catastrophic, as recommended in DSM-III-R. ${ }^{40}$ Axis V, Global Assessment of Function $(\mathrm{GAF})$, was assessed by use of a self-report version of the GAF Scale from 0 to 100 . Two GAF measures were collected, one for the last year ('GAF-1') and one for the 2 weeks ('GAF-2') preceeding the injury.

\section{Measures of postinjury symptoms}

The $R P Q$

This questionnaire, developed by King and coworkers, ${ }^{41}$ consists of sixteen items to rate changes in subjective symptoms after an mTBI. The scale uses five numerical categories, where $0=$ not experienced at all, $1=i$ is no longer a problem, $2=$ a mild problem, $3=$ a moderate problem and $4=$ a severe problem. The RPQ score is then calculated as 
the sum of all the symptom scores excluding ratings of 1 (as they indicate resolved symptoms).

\section{The RHFUQ}

This self-report questionnaire contains 10 items and covers a perceived change in ability in social and home activities. The scale uses five numerical categories, where $0=$ no change, $1=$ no change, but more difficult, $2=$ a mild change, $3=$ amoderate change and $4=$ avery marked change. ${ }^{42}$

\section{The Hospital Anxiety and Depression Scale (HADS)}

$\operatorname{HADS}^{43}$ was used to measure symptoms of anxiety and depression. It is a brief self-report test with 14 items (seven each for depression and anxiety). It was developed specifically to be used with non-psychiatric patients in medical and somatic settings. The respondent marks the most suitable alternative for each item on a 4-point Likert scale, and the responses are scored from 0 to 3 . The HADS has been extensively used, and its psychometric properties have been found to be good. ${ }^{445}$

\section{The Impact of Event Scale - Revised (IES-R)}

IES-R is a widely used self-report scale for assessing stress reactions after traumatic events. ${ }^{46}$ It contains 22 items where the respondent rates the frequency of stress reactions during the last week, with the following options: 0 (not at all), 1 (rarely), 3 (sometimes) and 5 (often). The scale is composed of three subscales associated with post-traumatic stress disorder (PTSD): intrusion, avoidance and hyperarousal. The IES-R has good psychometric properties. $^{47}$

\section{Preinjury behavioural and personality measures \\ The Swedish Universities Scales of Personality (SSP)}

SSP is a personality inventory standardised on a representative sample $(n=741)$ from the general Swedish population. ${ }^{48}$ The SSP is designed to measure only traits commonly associated with psychopathology (eg, anxiety proneness, extraversion and aggression-hostility). It consists of 91 items, divided into 13 subscales. Each item is expressed as a statement to which the respondent has four answers to choose from, ranging from 'Does not apply at all' to 'Applies completely' . Scores are summed and transformed to $\mathrm{T}$ scores (mean $=50, \mathrm{SD}=10)$ for men and women separately.

\section{The Sense of Coherence Scale (SOC)}

The SOC measures psychological resilience to stressful events and was developed by Antonovsky. ${ }^{49}$ The SOC scale contains three subcomponents: comprehensibility, manageability and meaningfulness. The scale consists of 29 statements, and the respondent marks his or her agreement on a 7-point Likert scale. It has been used previously in TBI research ${ }^{50}$ who found that SOC score was similar in a group of individuals with TBI many years postinjury when compared with non-disabled people. In patients with orthopaedic injuries, a high SOC score predicted a better outcome after surgery after 1 year. ${ }^{51}$
Alcohol Use Disorders Identification Test (AUDIT)

Screening for hazardous alcohol use was made by use of the AUDIT. ${ }^{52}$ The AUDIT consists of 10 items and measures alcohol consumption, drinking behaviour, adverse reactions and alcohol-related problems during the last 12 months. Each item is scored from 0 to 4 . A cut-off score of 8 or higher has been shown to have $\mathrm{s}$ sensitivity and specificity over $90 \%$ for hazardous alcohol use. ${ }^{52}$ It has been used in previous TBI research. ${ }^{53} 54$

\section{Patient and public involvement}

The design of the study, the choice of research question and outcome measures and the recruitment to and conduct of the study was performed by healthcare professionals with extensive professional experience of work with this group of patients and robust knowledge of previous research in the field. Patients were not involved in this process.

\section{Statistics}

All data were entered and analysed with IBM's SPSS. Categorical variables were summed into frequencies for each group and then analysed with $\chi^{2}$. For tables with small expected cell counts, the Fisher's exact test was used. For larger contingency tables with ordered data (eg, length of PTA), the linear-by-linear association test was used.

Numerical variables were first summarised with standard descriptives and checked for skewness. Variables with skewness exceeding significantly above one were subsequently analysed with a non-parametric method (Mann-Whitney U test). Otherwise, the Student's t-test was chosen for comparisons between the two outcome groups. If the Levene's test for equality of variances was found to be violated, a t-statistic not assuming homogeneity of variance was computed. ORs with CIs and $p$ values were calculated using logistic regression. Statistical significance was set at $\mathrm{p}<0.05$, and all tests were two tailed.

\section{RESULTS}

\section{Recruitment and 1-year outcome}

A total of 122 patients accepted the invitation and were included in the study. The initial recruitment process, including analysis of acceptance rate and differences between participating and the non-participating patients, is described in previous publications. ${ }^{1255}$

At the 1-year follow-up, 94 participants were still in the programme (attrition rate $23 \%$ ). The patients who dropped out $(n=28)$ did not differ from remaining patients with respect to $\operatorname{sex}\left(\chi^{2}(1)=1.00, \mathrm{p}=0.316\right)$, age $(t(120)=0.41, \mathrm{p}=0.967)$ or initial level of experienced symptoms as reported in RPQ $(t(116)=1.14, \mathrm{p}=0.257$. However, the patients who dropped out had fewer years of education $(M=10.8, S D$ 3.6) than remaining patients $(M=12.6, S D=2.6), t(110)=2.46, \mathrm{p}=0.015$.

Data on RPQ and RHFUQ at 1 year postinjury were analysed to create the two outcome groups. In RPQ 50 patients $(53 \%)$ reported having no remaining symptoms 
Table 1 Sociodemographic characteristics of patients with $\mathrm{mTBI}$ split into recovered by 1 year and those who reported both symptoms and disability (PCS)

\begin{tabular}{lll}
\hline Characteristic & $\begin{array}{l}\text { Recovered } \\
(\mathbf{n = 8 3})\end{array}$ & $\begin{array}{l}\text { PCS } \\
(\mathbf{n = 1 1 )}\end{array}$ \\
\hline Age, mean (SD) & $36.7(15.2)$ & $41.9(13.2)$ \\
\hline Sex, n (\%) & $54(65)$ & $3(27)$ \\
\hline Male & $29(35)$ & $8(73)$ \\
\hline Female & & \\
\hline Marital status, n (\%) & $20(24)$ & $3(27)$ \\
\hline Unmarried, living alone & $63(76)$ & $8(73)$ \\
\hline Married, living together & $12.7(2.6)$ & $11.6(2.7)$ \\
\hline Years of education, mean (SD) & & \\
\hline Occupational status, n (\%) & $63(76)$ & $6(55)$ \\
\hline Working & $15(18)$ & $0(0)$ \\
\hline Studying & $0(0)$ & $1(9)$ \\
\hline Unemployed & $1(1)$ & $4(36)$ \\
\hline Sick leave & $2(2)$ & $0(0)$ \\
\hline Disability pension & $2(2)$ & $0(0)$ \\
\hline Retirement pension & &
\end{tabular}

PCS, post-concussive symptoms.

at all, an additional 26 patients (28\%) reported just one or two remaining symptoms, and 18 (19\%) reported three or more remaining symptoms. This last number shows a decrease in this cohort from $33 \%$ PCS cases at 3 months postinjury, ${ }^{12}$ using symptom-only criteria. In RHFUQ, 78 patients $(83 \%)$ reported no disability, three patients (3\%) reported just one disability and the remaining 13 patients (14\%) reported two or more disabilities. Eleven patients (12\%) matched the combined criteria for PCS, which required three or remaining symptoms and two or more remaining disabilities. Remaining patients $(n=83)$ formed the recovered group.

\section{Sociodemographics}

There was a significant association between sex and outcome, $\chi^{2}(1)=5.81, p=0.022$. Based on the OR, women were 4.97 times more likely to end up in the PCS group, 95\% CI (1.22 to 20.17). There were no significant differences between the two groups with regard to age ( $t$ $(92)=-1.08, \mathrm{p}=0.281)$, years of education $(t(92)=1.24$, $\mathrm{p}=0.218)$ or marital status $\left(\chi^{2}(1)=0.53, \mathrm{p}=1.00\right)$. The details are presented in table 1 , along with occupational status. Occupational status at the time of injury showed significant differences between the two groups $\left(\chi^{2}\right.$ $(5)=33.24, p=<0.001)$ and was further analysed by visual inspection. A distinct difference between the two groups was that all students recovered by 1 year. Patients on sick leave at the time of the injury tended to develop PCS, while those on a pension (both retirement and disability) recovered.
Table 2 Peri-injury data for those who had recovered by 1 year and those who still reported post-concussive symptoms and disability (PCS)

\begin{tabular}{|c|c|c|}
\hline Characteristics & $\begin{array}{l}\text { Recovered } \\
(n=83)\end{array}$ & $\begin{array}{l}\text { PCS } \\
(n=11)\end{array}$ \\
\hline \multicolumn{3}{|l|}{ Type of injury event, n (\%) } \\
\hline Fall from height & $31(37)$ & $3(27)$ \\
\hline Fall from the same level & $17(20)$ & $1(9)$ \\
\hline Traffic & $17(20)$ & $3(27)$ \\
\hline Assaults & $9(11)$ & $0(0)$ \\
\hline Other & $9(11)$ & $4(36)$ \\
\hline \multicolumn{3}{|l|}{ Loss of consciousness, $n(\%)$} \\
\hline$<1 \min$ & $37(45)$ & $5(45)$ \\
\hline $1-5 \min$ & $31(37)$ & $6(55)$ \\
\hline $6-30 \mathrm{~min}$ & $15(18)$ & $0(0)$ \\
\hline \multicolumn{3}{|l|}{ Post-traumatic amnesia, n (\%) } \\
\hline$<1 \min$ & $10(12)$ & $4(36)$ \\
\hline $1-5 \min$ & $19(23)$ & $4(36)$ \\
\hline $6-45 \min$ & $34(41)$ & $1(9)$ \\
\hline$>45 \min$ & $20(24)$ & $2(18)$ \\
\hline \multicolumn{3}{|l|}{ GCS score, n (\%) } \\
\hline 15 & $73(88)$ & $10(91)$ \\
\hline 14 & $10(12)$ & $1(9)$ \\
\hline Retrograde amnesia & $11(13)$ & $0(0)$ \\
\hline Injury related changes on CT or MRI & $6(7)$ & $2(18)$ \\
\hline Intoxicated by alcohol, n (\%) & $22(27)$ & $1(9)$ \\
\hline Initial symptom severity*, mean (SD) & $10.4(9.3)$ & $23.8(17.0)$ \\
\hline
\end{tabular}

*Initial symptom severity was measured by the Rivermead Post-Concussion Symptoms Questionnaire. There was one missing protocol from the recovered group. The variable showed excessive skewness, and Mann-Whitney $U$ test was used as statistical method. However, here the values are shown since they are considered more informative. GCS, Glasgow Coma Scale.

\section{Medical data}

Data regarding acute injury characteristics for the two outcome groups at the 1-year follow-up are presented in table 2. The type of injury event did not affect outcome $\left(\chi^{2}(4)=6.91, \mathrm{p}=0.141\right)$, nor did a lower GCS score $\left(\chi^{2}\right.$ $(1)=0.82, p=1.00)$. Both LOC and PTA were divided into manageable time frames and cross-tabulated. No effect was found for LOC (linear-by-linear association=0.66, $\mathrm{p}=0.417$ ), but longer duration of PTA was associated with recovery (linear-by-linear association $=4.54, \mathrm{p}=0.033$ ). Eleven participants reported retrograde amnesia, four of them longer than $5 \mathrm{~min}$. All of those who reported retrograde amnesia belonged to the recovered group, but it did not reach significance $\left(\chi^{2}(1)=1.65, \mathrm{p}=0.351\right)$. No effect for alcohol intoxication $\chi^{2}(1)=1.47, \mathrm{p}=0.449$. Furthermore, alcohol intoxication at the time of injury was not associated with PTA $\left(\chi^{2}(3)=0.77, \mathrm{p}=0.857\right)$, LOC $\left(\chi^{2}(2)=2.69, \mathrm{p}=0.261\right)$ or retrograde amnesia $\left(\chi^{2}(1)=0.25, p=0.696\right)$. Injury-related changes on CT 
or MRI was evident in eight participants and not related to outcome $\left(\chi^{2}(1)=1.50, p=0.235\right)$, but to a lower initial $\operatorname{GCS}\left(\chi^{2}(1)=5.63, p=0.049\right)$. Initial symptom severity, as measured by the RPQ the day after the trauma, showed excessive skewness and was analysed with MannWhitney U test. The result showed that the PCS group (median=68.32) initially experienced significantly more symptoms than the recovered group (median=44.14), $\mathrm{U}=685,50, \mathrm{p}=0.005, r=0.29$.

\section{Psychiatric assessment}

Nine out of eleven PCS patients (83\%) had a previous or concurrent psychiatric disorder, established at the psychiatric assessment 1 week postinjury. This was significantly higher than in the recovered group where only 20 out of 83 participants (24\%) had a previous or concurrent disorder.

Forty-two of the recovered patients and 10 of the PCS patients reported psychosocial stress of at least moderate severity during the year before the injury, $\left(\chi^{2}(1)=6.38\right.$, $\mathrm{p}=0.020$ ). Total number of psychosocial stressors showed excessive skewness and was analysed with Mann-Whitney $\mathrm{U}$ test. The result showed that the PCS group also reported more stressors (median=73.55) than the recovered group (median=44.05), $\mathrm{U}=743.00, \mathrm{p}=0.001, \mathrm{r}=0.36$. The two self-rated GAF measures showed a negative skewness exceeding -1 and were consequently analysed with non-parametric analysis (Mann-Whitney $U$ test). Patients with PCS had significantly lower self-rated global functioning (median=35.61) than patients who had recovered (median=50.32) for the year before the injury, $\mathrm{U}=470.0$, $z=-2.11, p=0.035, r=-0.22$. For the 2 weeks before the injury, similar results were obtained with lower scores for patients with PCS (median=37.44) than patients who had recovered (median $=49.88$ ) but just short of being significant, $U=503.0, z=-1.77, \mathrm{p}=0.076, r=-0.18$. The results for the actual ratings are shown in table 3 .

\section{Preinjury behavioural and personality measures}

Participants who developed PCS reported significantly less resilience for stressful events in the SOC than those participants who recovered $(t(91)=2.44, \mathrm{p}=0.018, r=0.25)$. When breaking down the results in the three subcomponents of the scale, no significant differences were found concerning experienced comprehensibility or meaningfulness, but in manageability $(t(91)=2.79, \mathrm{p}=0.006$, $r=0.28)$.

To see if personality traits, as measured by the SSP, were associated with outcome, independent samples t-tests were performed. Levene's test for equality of variances was found to be violated for somatic trait anxiety $(F(92)=4.61$, $\mathrm{p}=0.034)$, embitterment $(F(92)=10.98, \mathrm{p}=0.001)$ and physical trait aggressivity $(F(92)=4.34, \mathrm{p}=0.40)$. For these traits, a t-statistic not assuming homogeneity of variance was computed. As can be seen in table 4, results indicate that patients with PCS had elevated somatic trait anxiety, embitterment and mistrust when compared with the group who had recovered. Previous alcohol consumption pattern did not differ between the two groups (see table 3$)$.

\section{Postinjury symptoms}

Both Impact of Event Scale and HADS showed excessive skewness $(>1)$ and was analysed using non-parametric methods (Mann-Whitney U test). The results showed that patients who developed PCS (median=68.45) reported

Table 3 Preinjury variables for patients with $\mathrm{mTBI}$ split into those who had recovered by 1 year and those who reported both symptoms and disability (PCS)

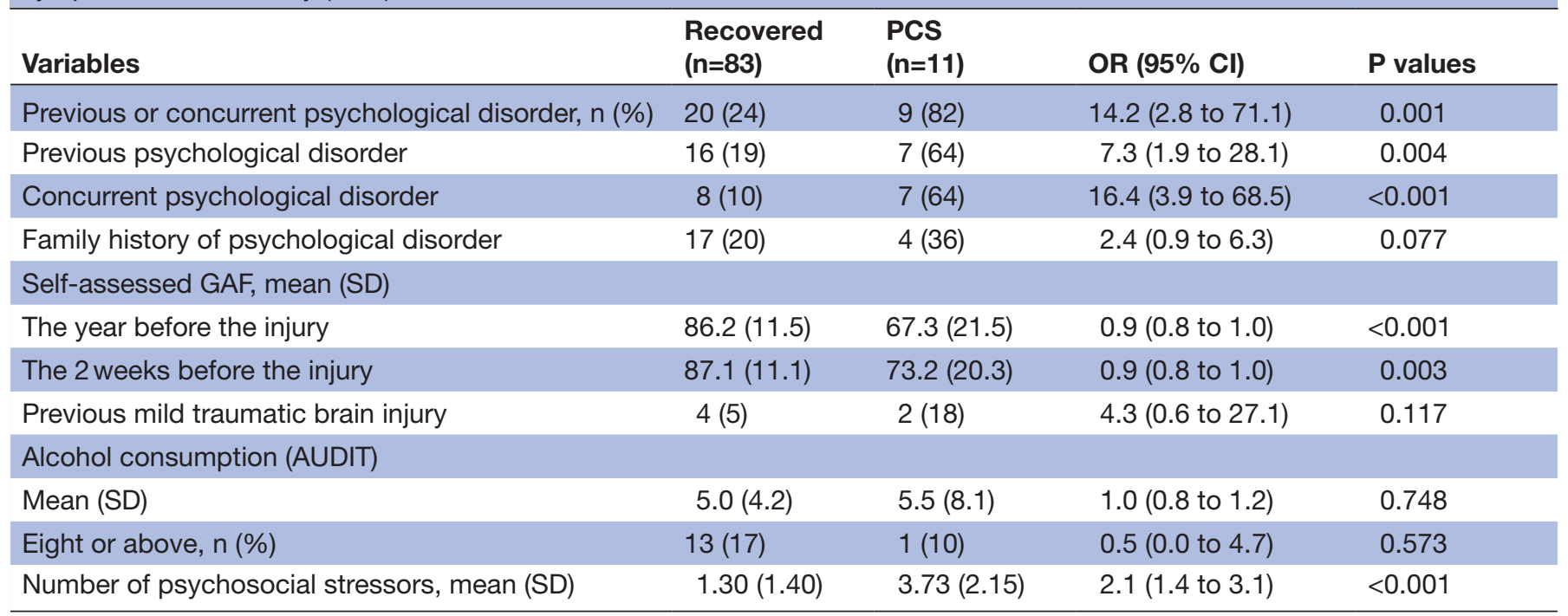

ORs with Cls and $\mathrm{p}$ values are calculated using logistic regression.

Note: there were eight missing questionnaires for AUDIT (seven for the recovered and one for the PCS group). There was one missing questionnaire for Sense of Coherence Scale.

AUDIT, Alcohol Use Disorders Identification Test; GAF, Global Assessment of Function; mTBI, mild traumatic brain injury; PCS, postconcussive symptoms. 
Table 4 Mean T-scores for the Swedish universities' scales of personality completed 1 week postinjury, split into those who had recovered by 1 year and those who reported both symptoms and disability (PCS)

\begin{tabular}{|c|c|c|c|c|c|c|}
\hline \multirow[b]{2}{*}{ Personality variable } & \multicolumn{2}{|c|}{$\begin{array}{l}\text { Recovered } \\
(n=83)\end{array}$} & \multicolumn{2}{|c|}{$\begin{array}{l}\text { PCS } \\
(n=11)\end{array}$} & \multirow[b]{2}{*}{$P$ values } & \multirow[b]{2}{*}{ Cohen's c } \\
\hline & M & SD & M & SD & & \\
\hline \multicolumn{7}{|l|}{ Anxiety proneness } \\
\hline Somatic trait anxiety & 45,3 & 7,8 & 53,8 & 11,0 & 0.030 & 0.89 \\
\hline Psychic trait anxiety & 45,4 & 9,1 & 49,8 & 11,6 & 0.156 & 0.42 \\
\hline Stress susceptibility & 46,9 & 10,4 & 52,1 & 15,1 & 0.145 & 0.40 \\
\hline Low assertiveness & 46,8 & 9,7 & 43,9 & 10,5 & 0.362 & -0.04 \\
\hline \multicolumn{7}{|l|}{ Extraversion } \\
\hline Impulsivity & 51,8 & 9,4 & 54,5 & 12,6 & 0.400 & 0.23 \\
\hline Adventure seeking & 54,1 & 9,3 & 55,9 & 7,7 & 0.558 & 0.21 \\
\hline Detachment & 44,2 & 8,7 & 47,7 & 8,9 & 0.216 & 0.40 \\
\hline Embitterment & 46,7 & 8,4 & 59,3 & 15,3 & 0.022 & 1.02 \\
\hline Social desirability & 54,4 & 9,7 & 51,3 & 9,6 & 0.311 & -0.32 \\
\hline \multicolumn{7}{|l|}{ Aggression-hostility } \\
\hline Verbal trait aggressivity & 50,4 & 8,4 & 51,0 & 11,1 & 0.823 & 0.06 \\
\hline Physical trait aggressivity & 47,2 & 9,0 & 53,6 & 14,6 & 0.185 & 0.53 \\
\hline Trait irritability & 46,2 & 10,9 & 52,0 & 14,6 & 0.112 & 0.45 \\
\hline Mistrust & 44,5 & 10,7 & 55,1 & 13,2 & 0.004 & 0.88 \\
\hline
\end{tabular}

PCS, post-concussive symptoms.

more initial post-traumatic stress than patients who later recovered (median $=44.72$ ), $U=687.00, z=2.72, \mathrm{p}=0.007$, $r=0.28$. Looking further at the subscales revealed that the two groups differed significantly only in hyperarousal, with the PCS group (median=75.91) reporting more distress than the recovered group (median=43.73), $U=769.00$, $z=3.74, \mathrm{p}=0.000, r=0.39$. There were highly significant differences between the two groups on emotional distress as measured by HADS. One week postinjury, the PCS group (median=72.41) experienced higher levels of anxiety than the recovered group (median=44.20), $U=730.50$, $z=3.30, \mathrm{p}=0.001, r=0.34$. The PCS group (median=72.77) also experienced more symptoms of depression than the recovered group (median $=44.15), U=734.50, z=3.32$, $\mathrm{p}=0.001, r=0.34$. The parametric mean and SD for both scales are shown in table 5 .

\section{DISCUSSION}

The main purpose of this study was to examine if aspects of emotional reserve were associated with the development of PCS after mTBI to complete our previous

Table 5 The results from measures of post-traumatic and emotional symptoms at 1 week postinjury for the two outcome groups: recovered and those who still reported symptoms and disability (PCS) at 1 year postinjury

\begin{tabular}{|c|c|c|c|c|c|c|}
\hline \multirow[b]{2}{*}{ Variable } & \multicolumn{2}{|c|}{$\begin{array}{l}\text { Recovered } \\
(n=83)\end{array}$} & \multicolumn{2}{|c|}{$\begin{array}{l}\text { PCS } \\
(n=11)\end{array}$} & \multirow[b]{2}{*}{ OR (Cl) } & \multirow[b]{2}{*}{$P$ values } \\
\hline & $\mathbf{M}$ & SD & $\mathbf{M}$ & SD & & \\
\hline \multicolumn{7}{|c|}{ Impact of Event Scale } \\
\hline Intrusions & 6.2 & 5.4 & 15.2 & 14.7 & 1.1 (1.0 to 1.2$)$ & 0.002 \\
\hline Avoidance & 4.8 & 6.7 & 9.3 & 10.2 & 1.1 (1.0 to 1.2$)$ & 0.070 \\
\hline Hyperarousal & 3.5 & 4.3 & 12.4 & 8.7 & $1.2(1.1$ to 1.4$)$ & $<0.001$ \\
\hline Total & 14.5 & 14.5 & 36.8 & 30.0 & 1.1 (1.0 to 1.1$)$ & 0.001 \\
\hline \multicolumn{7}{|c|}{ Hospital Anxiety and Depression Scale } \\
\hline Anxiety & 2.7 & 3.3 & 8.4 & 5.7 & 1.3 (1.1 to 1.6$)$ & $<0.001$ \\
\hline Depression & 2.2 & 2.6 & 6.7 & 4.7 & 1.4 (1.1 to 1.7$)$ & $<0.001$ \\
\hline
\end{tabular}

ORs with $\mathrm{Cls}$ and $\mathrm{p}$ values are calculated using logistic regression.

PCS, post-concussive symptoms. 
findings regarding cognitive reserve in the same cohort. ${ }^{12}$ At the 1-year follow-up, $12 \%$ of this cohort fulfilled our extended criteria for PCS, including both symptoms and disability.

Factors related to the actual injury, so-called peri-injury factors were, in general, not related to outcome, with one notable exception: the PCS group reported more initial injury symptoms. This could theoretically be interpreted as a sign of severity of the underlying injury. However, most evidence suggests that objective acute injury factors are not related to late outcome, so it is unlikely that the actual injury was more serious. A more feasible view is that the reporting of a large number of initial symptoms after a mTBI is merely another marker for the preinjury psychological vulnerability in the PCS group that already at a very early stage after the injury shapes the emergence and later on the persistence of symptoms and disability.

The weight of preinjury factors emerged markedly. The PCS group reported a greater number of psychosocial stressors for the year preceding the injury, corroborating previous findings. ${ }^{56} \mathrm{We}$ found that individuals with a previous or concurrent psychiatric disorder, or with a family history of such disorder, were more likely to develop PCS. Both GAF ratings were significantly lower, corroborating and extending earlier findings. ${ }^{13} 3233$ Despite the elevated frequency of $15 \%$ of alcohol abuse in the cohort, there were no differences in the number of intoxicated patients or alcohol abuse between PCS and recovered patients. Among the postinjury factors, higher levels of PTSD symptoms as assessed by the IES-R, in particular the subscale of hyperarousal, showed a clear association to PCS. Also, both anxiety and depression were higher in PCS patients 1 week after trauma. The findings are further supported by the design of the study, since data were obtained within a week after the mTBI, minimising recall bias and before the development of prolonged PCS symptoms, minimising the risk for confirmation bias.

We used the SSP to measure different aspects of personality and found in the PCS group elevated level of somatic anxiety, but not psychic anxiety, compared with the recovered group. The SSP divides trait anxiety into a psychic and a somatic component. ${ }^{48}{ }^{57}$ This division of anxiety was first suggested by Eysenck ${ }^{58}$ where the somatic component reflects autonomous over-reactivity, and the mental component reflects brooding and worrying behaviour. Furthermore, the PCS group had significantly higher levels of mistrust. This SSP scale has its origins in the subscale suspicion in the Buss-Durkee Hostility Inventory $^{59}$ and measures traits of being suspicious and distrusting of other people's motives. The elevated level of embitterment in the PCS group may be linked to coping responses during stressful life events. The SSP scale can be illustrated by the following item: 'I had often gotten into trouble even when it was not my fault'. Blaming others has previously been found to influence symptom reporting in patients with mTBI ${ }^{60}$ To sum it up, a pattern of higher reactivity in the autonomic nervous system, and some personality traits (embitterment and suspiciousness) may lead to more stress in everyday life, and an increased sensitivity when encountering and managing traumatic events, such as a brain injury.

We used a different measure of psychological resilience in connection with mTBI than other studies, ${ }^{26}$ but the findings were similar: lower levels were linked to PCS development. The three-factor construction of the SOC allows further analysis of different aspects of resilience: comprehensibility, manageability and meaningfulness. We found that only manageability was significantly lower in the PCS group. This subscale is tapping into an underlying construct of being in control of one's life and a sense of mastery. To our knowledge, this finding has not been reported before.

Thus, the outcome differed despite seemingly similar brain trauma, highlighting the importance of biopsychosocial factors for the development of PCS,${ }^{61}$ such as the extent of cognitive ${ }^{17}$ and emotional reserve. ${ }^{36}$

As mentioned before, the peri-injury factors were hardly related to outcome in this study. Injury-related changes found on MRI or CT scan and initial lower GCS score were not related to PCS, which is in line with previous findings. ${ }^{62}{ }^{63}$ However, PCS patients reported a shorter duration of PTA. However, there were only few individuals with imaging findings and the GCS score was restricted to 14 or 15 , so the sample was too small to enable the detection of differences.

\section{Strengths and limitations}

The study had a prospective design and included all patients within the first 24 hours after the trauma when injury-related factors could be reliably assessed. Preinjury factors were thoroughly assessed soon after injury, minimising recall bias. ${ }^{64} \mathrm{~A}$ further strength is the comprehensive psychiatric assessment by a senior psychiatrist, instead of solely relying on self-report questionnaires. In previous studies ${ }^{1332}$ psychiatric assessments have yielded decreased estimates of PCS. The assessment of preinjury factors was performed without knowledge of late outcome.

The small size of the PCS group is a limitation, and relevant findings may have remained undetected due to low power. There is also a substantial lack of precision, which can be seen in the wide CIs. Larger prospective samples are thus required to corroborate the present results. Furthermore, the association between attrition and limited education is problematic, causing restricted generalisability. Finally, the symptoms and disabilities in the PCS definition show some overlap with psychiatric conditions, and previous as well as concurrent psychiatric disorders turned out to be risk factors for PCS. Given the many other psychosocial determinants for PCS found in our study, a biopsychosocial approach, taking the psychiatric comorbidities into account, is likely to yield the most thorough understanding of the emergence and persistence of symptoms and disability after mTBI.

In conclusion, the present findings fit and extend Gallo and Matthews ${ }^{20}$ Reserve-Capacity Model, demonstrating a link between psychosocial adjustment and 
specific symptom development after an injury. The results demonstrate the importance of intrapersonal emotional reserve for symptom development along with cognitive reserve, complementing our previous findings. Thus, the variations seen in outcome after mTBI may to a considerable degree reflect individual differences in emotional and cognitive coping ability. The results highlight the importance of considering psychiatric history when identifying patients at risk of developing PCS and emphasise the value of considering these preinjury factors in clinical management.

Acknowledgements The authors wish to thank professor emeritus Jörgen Borg, the primary investigator of the original study, Seija Lundh, registered nurse and Daniel Karlsted and Siw Evans, licenced psychologists for their contribution during recruitment and data collection and all participants who devoted time and engagement to make this study possible.

Contributors $C O, A L$ and $A B$ conceived of the present study. $A L, G E, C N d B$ and $A B$ initiated the study design. $A L$ and $C N d B$ contributed to data collection. GE provided statistical expertise. All authors contributed to the interpretation of the study results as well as the writing of the manuscript. All authors have read and agree with the manuscript's final content.

Funding This study was supported by grants from: The Swedish insurance company AFA, Hjärnskadeförbundet Hjärnkraft, a Swedish organisation for people with acquired brain injury, The Promobilia Foundation, Svenska Läkaresällskapet (The Swedish Medical Association).

Competing interests None declared.

Patient consent Obtained.

Ethics approval The study was approved by the regional ethical board for Stockholm, Sweden.

Provenance and peer review Not commissioned; externally peer reviewed. Data sharing statement There are no unpublished data available.

Open access This is an open access article distributed in accordance with the Creative Commons Attribution Non Commercial (CC BY-NC 4.0) license, which permits others to distribute, remix, adapt, build upon this work non-commercially, and license their derivative works on different terms, provided the original work is properly cited and the use is non-commercial. See: http://creativecommons.org/ licenses/by-nc/4.0/

(C) Article author(s) (or their employer(s) unless otherwise stated in the text of the article) 2018. All rights reserved. No commercial use is permitted unless otherwise expressly granted.

\section{REFERENCES}

1. Carroll LJ, Cassidy JD, Peloso PM, et al. Prognosis for mild traumatic brain injury: results of the WHO Collaborating Centre Task Force on Mild Traumatic Brain Injury. J Rehabil Med 2004(43 Suppl):84-105.

2. Cassidy JD, Cancelliere C, Carroll LJ, et al. Systematic review of selfreported prognosis in adults after mild traumatic brain injury: results of the International Collaboration on Mild Traumatic Brain Injury Prognosis. Arch Phys Med Rehabil 2014;95(3 Suppl):S132-51.

3. Lannsjö M, af Geijerstam JL, Johansson U, et al. Prevalence and structure of symptoms at 3 months after mild traumatic brain injury in a national cohort. Brain Inj 2009;23:213-9.

4. Dischinger PC, Ryb GE, Kufera JA, et al. Early predictors of postconcussive syndrome in a population of trauma patients with mild traumatic brain injury. J Trauma 2009;66:289-97.

5. Elgmark Andersson E, Emanuelson I, Björklund R, et al. Mild traumatic brain injuries: the impact of early intervention on late sequelae. A randomized controlled trial. Acta Neurochir 2007;149:151-60.

6. Andersson EE, Bedics BK, Falkmer T. Mild traumatic brain injuries: a 10-year follow-up. J Rehabil Med 2011;43:323-9.

7. Belanger HG, Curtiss G, Demery JA, et al. Factors moderating neuropsychological outcomes following mild traumatic brain injury: a meta-analysis. J Int Neuropsychol Soc 2005;11:215-27.
8. Binder LM. A review of mild head trauma. Part II: Clinical implications. J Clin Exp Neuropsychol 1997;19:432-57.

9. Frencham KA, Fox AM, Maybery MT. Neuropsychological studies of mild traumatic brain injury: a meta-analytic review of research since 1995. J Clin Exp Neuropsychol 2005;27:334-51.

10. Schretlen DJ, Shapiro AM. A quantitative review of the effects of traumatic brain injury on cognitive functioning. Int Rev Psychiatry 2003;15:341-9.

11. Godbolt AK, Cancelliere C, Hincapié CA, et al. Systematic review of the risk of dementia and chronic cognitive impairment after mild traumatic brain injury: results of the International Collaboration on Mild Traumatic Brain Injury Prognosis. Arch Phys Med Rehabil 2014;95(3 Suppl):S245-56.

12. Oldenburg C, Lundin A, Edman G, et al. Cognitive reserve and persistent post-concussion symptoms--A prospective mild traumatic brain injury (mTBI) cohort study. Brain Inj 2016;30:146-55.

13. Luis CA, Vanderploeg RD, Curtiss G. Predictors of postconcussion symptom complex in community dwelling male veterans. J Int Neuropsychol Soc 2003;9:1001-15.

14. Fay TB, Yeates KO, Taylor HG, et al. Cognitive reserve as a moderator of postconcussive symptoms in children with complicated and uncomplicated mild traumatic brain injury. $J$ Int Neuropsychol Soc 2010;16:94-105.

15. Stulemeijer M, van der Werf S, Borm GF, et al. Early prediction of favourable recovery 6 months after mild traumatic brain injury. $J$ Neurol Neurosurg Psychiatry 2008;79:936-42.

16. Satz P. Brain reserve capacity on symptom onset after brain injury: A formulation and review of evidence for threshold theory. Neuropsychology 1993;7:273-95.

17. Bigler ED, Stern Y. Traumatic brain injury and reserve. Handb Clin Neurol 2015;128:691-710.

18. Stern Y. Cognitive reserve. Neuropsychologia 2009;47:2015-28.

19. Feinstein JS. The relationship between socioeconomic status and health: a review of the literature. Milbank Q 1993;71:279-322.

20. Gallo LC, Matthews KA. Understanding the association between socioeconomic status and physical health: do negative emotions play a role? Psychol Bull 2003;129:10-51.

21. Kay T, Newman B, Cavallo M, et al. Toward a neuropsychological model of functional disability after mild traumatic brain injury. Neuropsychology 1992;6:371-84.

22. Rush BK, Malec JF, Moessner AM, et al. Preinjury Personality Traits and the Prediction of Early Neurobehavioral Symptoms Following Mild Traumatic Brain Injury. Rehabil Psychol 2004;49:275-81.

23. Garden N, Sullivan KA, Lange RT. The relationship between personality characteristics and postconcussion symptoms in a nonclinical sample. Neuropsychology 2010;24:168-75.

24. Yuen KM, Tsai YH, Lin WC, et al. Retrospectively evaluated preinjury personality traits influence postconcussion symptoms. Appl Neuropsychol Adult 2016;23:322-32.

25. Losoi H, Silverberg ND, Wäljas M, et al. Resilience Is Associated with Outcome from Mild Traumatic Brain Injury. J Neurotrauma 2015;32:942-9.

26. Sullivan KA, Kempe CB, Edmed SL, et al. Resilience and Other Possible Outcomes After Mild Traumatic Brain Injury: a Systematic Review. Neuropsychol Rev 2016;26:173-85.

27. Sullivan KA, Edmed SL, Allan AC, et al. The role of psychological resilience and $\mathrm{mTBI}$ as predictors of postconcussional syndrome symptomatology. Rehabil Psychol 2015;60:147-54.

28. Merritt VC, Lange RT, French LM. Resilience and symptom reporting following mild traumatic brain injury in military service members. Brain Inj 2015;29:1325-36.

29. McCauley SR, Wilde EA, Miller ER, et al. Preinjury resilience and mood as predictors of early outcome following mild traumatic brain injury. J Neurotrauma 2013;30:642-52.

30. King NS. Post-concussion syndrome: clarity amid the controversy? Br J Psychiatry 2003;183:276-8.

31. Meares S, Shores EA, Taylor AJ, et al. Mild traumatic brain injury does not predict acute postconcussion syndrome. $J$ Neurol Neurosurg Psychiatry 2008;79:300-6.

32. Meares S, Shores EA, Taylor AJ, et al. The prospective course of postconcussion syndrome: the role of mild traumatic brain injury. Neuropsychology 2011;25:454-65.

33. Ponsford J, Willmott $\mathrm{C}$, Rothwell $\mathrm{A}$, et al. Factors influencing outcome following mild traumatic brain injury in adults. J Int Neuropsychol Soc 2000;6:568-79.

34. Snell DL, Siegert RJ, Hay-Smith EJ, et al. Associations between illness perceptions, coping styles and outcome after mild traumatic brain injury: preliminary results from a cohort study. Brain Inj 2011;25:1126-38. 
35. American Psychiatric Association. Diagnostic and statistical manual of mental disorders: DSM-IV-TR. 4th ed. Washington, DC: American Psychiatric Association, 2000

36. Sela-Kaufman M, Rassovsky Y, Agranov E, et al. Premorbid personality characteristics and attachment style moderate the effect of injury severity on occupational outcome in traumatic brain injury: another aspect of reserve. J Clin Exp Neuropsychol 2013;35:584-95.

37. Nygren De Boussard C, Fredman P, Lundin A, et al. S100 in mild traumatic brain injury. Brain Inj 2004;18:671-83.

38. Gómez PA, Lobato RD, Ortega JM, et al. Mild head injury: differences in prognosis among patients with a Glasgow Coma Scale score of 13 to 15 and analysis of factors associated with abnormal CT findings. Br J Neurosurg 1996;10:453-60.

39. Uchino Y, Okimura Y, Tanaka M, et al. Computed tomography and magnetic resonance imaging of mild head injury--is it appropriate to classify patients with Glasgow Coma Scale score of 13 to 15 as "mild injury"? Acta Neurochir 2001;143:1031-7.

40. American Psychiatric Association. Diagnostic and statistical manual of mental disorders: DSM-III-R. 3 rev edn. Cambridge: American Psychiatric Association, 1987

41. King NS, Crawford S, Wenden FJ, et al. The Rivermead Post Concussion Symptoms Questionnaire: a measure of symptoms commonly experienced after head injury and its reliability. $J$ Neurol 1995;242:587-92.

42. Crawford S, Wenden FJ, Wade DT. The Rivermead head injury follow up questionnaire: a study of a new rating scale and other measures to evaluate outcome after head injury. J Neurol Neurosurg Psychiatry 1996;60:510-4

43. Zigmond AS, Snaith RP. The hospital anxiety and depression scale. Acta Psychiatr Scand 1983;67:361-70.

44. Herrmann C. International experiences with the Hospital Anxiety and Depression Scale--a review of validation data and clinical results. $J$ Psychosom Res 1997;42:17-41.

45. Bjelland I, Dahl AA, Haug TT, et al. The validity of the Hospital Anxiety and Depression Scale. An updated literature review. J Psychosom Res 2002;52:69-77.

46. Weiss DS, Marmar CR. The Impact of Event Scale - Revised. In: Wilson JP, Keane TM, eds. Assessing psychological trauma and PTSD: A Practitioner's Handbook. New York: Guilford Press, 1997:399-411.

47. Sundin EC, Horowitz MJ. Impact of Event Scale: psychometric properties. Br J Psychiatry 2002;180:205-9.

48. Gustavsson JP, Bergman H, Edman G, et al. Swedish universities Scales of Personality (SSP): construction, internal consistency and normative data. Acta Psychiatr Scand 2000;102:217-25.

49. Antonovsky A. The structure and properties of the sense of coherence scale. Soc Sci Med 1993;36:725-33.
50. Jacobsson LJ, Westerberg M, Malec JF, et al. Sense of coherence and disability and the relationship with life satisfaction $6-15$ years after traumatic brain injury in northern Sweden. Neuropsychol Rehabil 2011;21:383-400.

51. Ristner G, Andersson R, Johansson LM, et al. Sense of coherence and lack of control in relation to outcome after orthopaedic injuries. Injury 2000;31:751-6.

52. Saunders JB, Aasland OG, Babor TF, et al. Development of the Alcohol Use Disorders Identification Test (AUDIT): WHO Collaborative Project on Early Detection of Persons with Harmful Alcohol Consumption--II. Addiction 1993;88:791-804.

53. Ponsford J, Whelan-Goodinson R, Bahar-Fuchs A. Alcohol and drug use following traumatic brain injury: a prospective study. Brain Inj 2007;21(13-14):1385-92.

54. Ponsford J, Tweedly L, Taffe J. The relationship between alcohol and cognitive functioning following traumatic brain injury. J Clin Exp Neuropsychol 2013;35:103-12.

55. Lundin A, de Boussard C, Edman G, et al. Symptoms and disability until 3 months after mild TBI. Brain Inj 2006;20:799-806.

56. van Veldhoven LM, Sander AM, Struchen MA, et al. Predictive ability of preinjury stressful life events and post-traumatic stress symptoms for outcomes following mild traumatic brain injury: analysis in a prospective emergency room sample. J Neurol Neurosurg Psychiatry 2011;82:782-7.

57. Schalling D, Asberg M, Edman G, et al. Markers for vulnerability to psychopathology: temperament traits associated with platelet MAO activity. Acta Psychiatr Scand 1987;76:172-82.

58. Eysenck HJ. Handbook of abnormal psychology, an experimental approach. 1st ed. New York: Basic Books, 1961.

59. Buss $A H$, Durkee $A$. An inventory for assessing different kinds of hostility. J Consult Psychol 1957;21:343-9.

60. Rutherford WH. Sequelae of concussion caused by minor head injuries. Lancet 1977;1:1-4.

61. Iverson GL, Silverberg N, Lange RT, et al. Conceptualizing Outcome from Mild Traumatic Brain Injury. In: Zasler ND, Katz DI, Zafonte RD, eds. Brain Injury Medicine - Principles and Practice. 2 edn. New York: Demos Medical Publishing, 2013.

62. Lannsjö M, Backheden M, Johansson U, et al. Does head CT scan pathology predict outcome after mild traumatic brain injury? Eur $J$ Neurol 2013;20:124-9.

63. Iverson GL, Lange RT, Wäljas M, et al. Outcome from Complicated versus Uncomplicated Mild Traumatic Brain Injury. Rehabil Res Pract 2012;2012:1-7

64. Ferguson RJ, Mittenberg W, Barone DF, et al. Postconcussion syndrome following sports-related head injury: expectation as etiology. Neuropsychology 1999;13:582-9. 